\title{
Lobular Capillary Hemangioma of Head and Neck Region: A Retrospective Study in A Tertiary Centre
}

\author{
Tulachan Bishow ${ }^{*}$, Roshan Acharya ${ }^{2}$ and Paras Poudel ${ }^{3}$ \\ ${ }^{1}$ Associate Professor, Department of ENT-HNS, Universal College of Medical Sciences, Nepal \\ ${ }^{2}$ Lecturer, Department of ENT-HNS, Universal College of Medical Sciences, Nepal
}

${ }^{3}$ Post Graduate Resident, Department of ENT, Universal College of Medical Sciences, Nepal

*Corresponding author: Bishow Tulachan, Department of ENT-HNS, Universal College of Medical Sciences (UCMS), Teaching hospital, Affiliated to Tribhuvan University, Nepal

\begin{abstract}
Background: Lobular capillary hemangiomas (LCH) are uncommon benign vascular entity of unknown etiology. Their prime locations are skin and mucosa of oral cavity, however, the nasal cavity involvement is very rare pertaining to head and neck vascular lesions. Here, we have retrospectively analyzed the confirmed LCH cases including sites, clinical features, radiological findings, treatments, and histological results.

Materials and Methods: A retrospective study carried out in Department of Ear, Nose and Throat and Head and Neck Surgeries (ENT-HNS) of Universal College of Medical Sciences, Tribhuvan University Teaching Hospital (UCMS, TUTH), Bhairahawa, Nepal. All the data of 10 cases (from June 2014 to February 2020) were collected from the OT (operation theatre) register and hospital records section. Data were analyzed for symptoms, possible etiologic factors, demographic profile, CT findings, histopathological features, and treatment modalities.

Results: Unilateral nasal obstruction with nasal mass and intermittent epistaxis (90\%) were the chief complaints. Female predominance was favored. In $80 \%$ of the patients, the mass was arising from the anterior nasal septum, in $10 \%$ from the anterior end of the inferior turbinate and in 10\% from the upper lip. GA (general anesthesia) was used in 20\% of cases whereas LA (local anesthesia) was used in $80 \%$ of the cases. All patients were managed successfully with no recurrence at follow up of 6 months.

Conclusion: It is a rare benign vascular entity with slight female predominance. It bears a less morbidity and recurrences on surgical excision but should be differentially diagnosed rightly so as to minimize aggressive management.
\end{abstract}

Keywords: Capillary hemangioma; nasal cavity; vascular lesion

Abbreviations: LCH: Lobular Capillary Hemangiomas; LA: Local Anesthesia; GA: General Anesthesia; ENT-HNS: Ear, Nose and Throat and Head and Neck Surgeries; OT: Operation Theatre; HPE: Histopathology Evaluation

\section{Introduction}

Lobular capillary hemangioma (LCH) is synonymously known as pyogenic granuloma, epulis gravidarum, eruptive hemangioma, granulation tissue-type hemangioma, granuloma gravidarum, pregnancy tumor and botryomycome [1-3]. It is a benign, fast growing, capillary proliferation with a microscopically distinct lobular architecture that affects the skin and mucous membranes of the oral and, rarely, of the nasal cavities and internal organs such as brain and liver [4-9]. Poncet and Dor were the first ones to describe it in 1897 as human botryomycosis and referred to these tumors as small vascular tumors in the fingers of four patients $[1,7,10,11]$. Oral cavity mucosa is the predominant site for LCH occurrence, but nasal cavity involvement is rare. Anterior septum (Little's area) is the most frequently affected site followed by turbinate, but lesions have also been described arising from the maxillary sinus, roof of nasal cavity and floor of nasal vestibule 
$[3,7,8]$. The exact pathogenesis seems to be debatable but it's linked with microtrauma (nose picking or nasal packing resulting in the overgrowth of granulation tissue) and hormonal factors such as pregnancy and oral contraceptive use as possible etiologies and other plausible being viral oncogenes, microscopic arterial venous malformations and over production of angiogenic growth factors [3-7]. Patients usually present with painless intermittent epistaxis, progressive unilateral nasal obstruction, and nasal mass of a short period. There's equal distribution between men and women in all ages however some studies show female predilection in the third to fifth decades $[7,8,12-14]$. The aim of this retrospective study is to analyze the clinical presentation, histological and radiological findings, and the treatment strategy.

\section{Materials and Methods}

This is a retrospective study carried out in Department of Ear, Nose and Throat and Head and Neck Surgeries (ENT-HNS) of Universal College of Medical Sciences, Tribhuvan University Teaching Hospital (UCMS, TUTH), Bhairahawa, Nepal. All the data (from June 2014 to February 2020) were collected from the OT (operation theatre) register and hospital records section. Institutional ethical clearance has been obtained. Meantime patients were informed about the future possibility of paper publication and the use of their hospital records use and the pictures too.

\section{Inclusion Criteria}

All patients with confirmed HPE (histopathology evaluation) of LCH of the nose.

\section{Exclusion Criteria}

Patients with bleeding diathesis, and other comorbidities. Information regarding symptoms, possible etiologic factors, demographic profile, CT findings, histopathological features, and treatment modalities were reviewed. All the cases were done in the OT using either general or local anesthesia. All cases underwent surgical excision and electrocauterization of the base and sent for histopathological evaluation. Zero-degree rigid endoscopy was used in 3 cases and headlight was used in 7 cases. After the anesthetization of the case, $5 \mathrm{ml}$ of $2 \%$ Xylocaine with 1:200000 Adrenaline was locally infiltrated. Ribbon gauze packs impregnated with Oxymetazoline nasal drops and $5 \mathrm{ml}$ of $4 \%$ Xylocaine were kept for 10 minutes then the procedure was performed. Soframycin ointment impregnated ribbon gauze pack were kept for 1 day unilaterally. Patients were discharged on the same day on oral Ciprofloxacin and analgesics. On next day, the nasal pack was removed in the OPD and topical Mupirocin ointment was prescribed for 2 weeks.

\section{Results}

There were total of 10 cases. 2 (20\%) were male and 8 (80\%) female patients (table 1 ) with male to female ratio of $1: 4$. The mean age was 30.6 years, ranging from 18 to 57 (Table 1) 1 male and 3 females were in the 5th decade. 2 female patients had a history of oral contraceptives intake. 1 male and 4 females had history of frequent nose picking habit. In 9 patients, the chief complaints were unilateral rapidly growing nasal mass, intermittent epistaxis and nasal obstruction and rhinorrhea in 1 patient. In 1 male patient (18 years old) the complaint was rapidly growing painless growth in the upper lip. In 1 female patient in the 5the decade the mass was arising from the inferior turbinate (left side) (Figures 1-6) and the rest being from the anterior end of nasal septum ( 6 on the right side and 2 on the left). The mean duration of symptoms was 2-3 months in the majority however 1 female patient in the 5 th decade was having for 6-8th months and 1 male patient had it since childhood (Table 1). Endoscopic removal was used in 3 cases and 7 were dealt with headlight. On examination, the mass ranges from $1.5-2.5 \mathrm{~cm}$ in size and was single dark red to polypoidal which bleed easily on brisk touch by the instrument. CT was suggestive of well-defined, enhancing soft tissue density lesions without bony erosions. Maxillary mucosal thickening (ipsilateral) was found in 1 patient (13.3\%). There were no postoperative complications with 1 recurrence case who lost to follow up till date (Table 1). Histopathology showed section of ulceration and granulation with underlying stroma of increased proliferation of small calibered blood vessels lined by plump of flattened endothelial cells; few in staghorn pattern and vaguely arranged in lobules. Intervening stroma is fibro collagenous and also shows loose, edematous areas along with mixed inflammatory cells comprised of lymphocytes, plasma cells, and neutrophils. Areas of necrosis is also evident. No atypia.

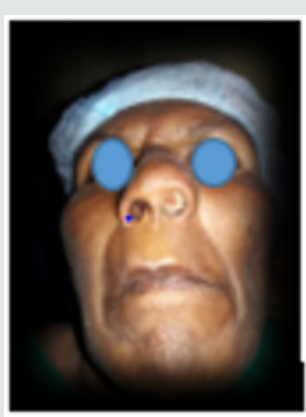

Figure 1: A red colored polypoidal mass in left nasal cavity.

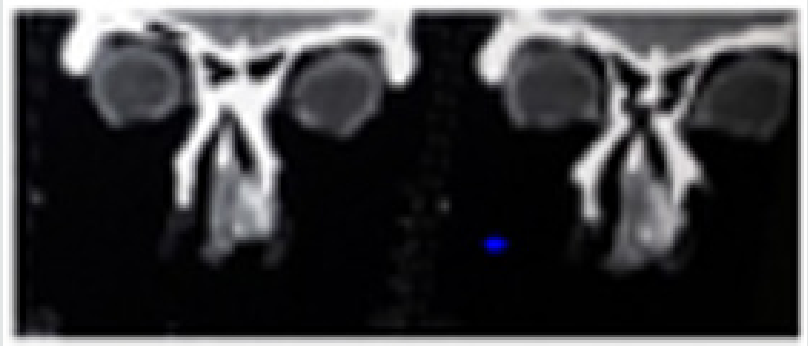

Figure 2: Coronal CT showing heterodense soft tissue density in left inferior turbinate. 


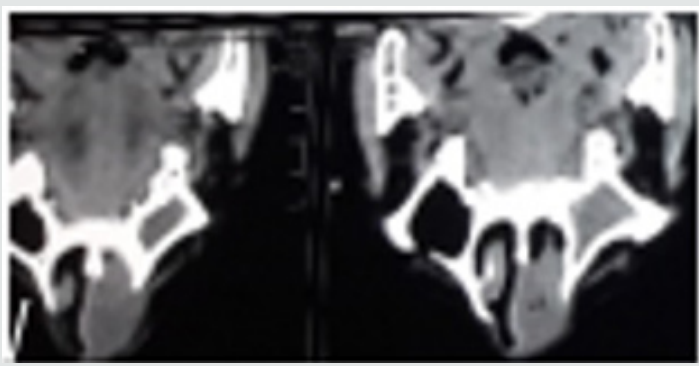

Figure 3: Axial CT showing soft tissue density in left nasal cavity.

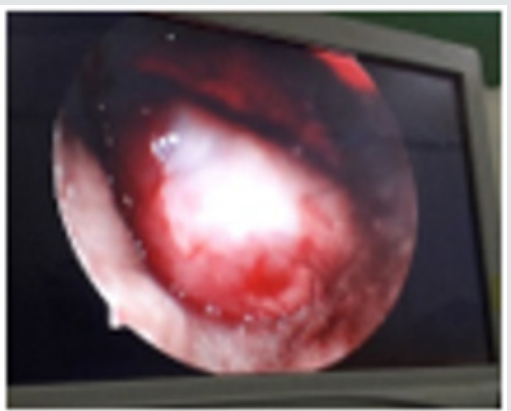

Figure 4: Endoscopic view of left nasal mass attached to left inferior turbinate.

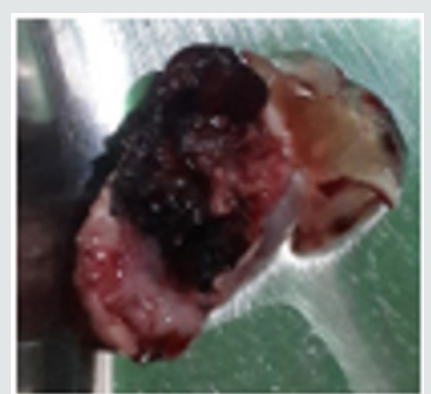

Figure 5: In toto excised mass $3 \times 2.5 \times 2.5 \mathrm{~cm}$.

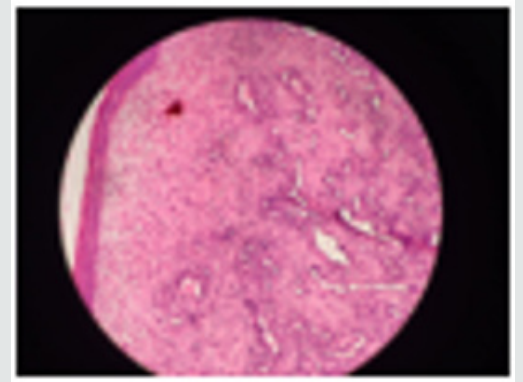

Figure 6: Hematoxylin \& eosin stained picture of capillary lobular hemangioma.

Table 1: Demographic characteristics of patients with lobular capillary hemangiomas of the head and neck region.

\begin{tabular}{|c|c|c|c|c|c|c|c|}
\hline No. & Gender & Age (years) & $\begin{array}{c}\text { Duration of } \\
\text { symptoms } \\
\text { (months) }\end{array}$ & Symptoms & Lesion site & Treatment & $\begin{array}{l}\text { Follow up } \\
\text { (months) }\end{array}$ \\
\hline 1. & Male & 55 & $21 / 2$ & $\begin{array}{c}\text { Nasal mass, intermittent } \\
\text { bleeding }\end{array}$ & $\begin{array}{l}\text { Right nasal } \\
\text { septum }\end{array}$ & $\begin{array}{l}\text { Removal and electrocautery } \\
\text { under LA (headlight) }\end{array}$ & 6 \\
\hline 2. & Male & 18 & Since childhood & $\begin{array}{c}\text { swelling with } \\
\text { intermittent bleeding }\end{array}$ & Upper lip & $\begin{array}{c}\text { Removal and electrocautery } \\
\text { under GA (headlight) }\end{array}$ & 6 \\
\hline 3. & Female & 22 & 2 & $\begin{array}{c}\text { Nasal mass, intermittent } \\
\text { bleeding }\end{array}$ & Right & $\begin{array}{l}\text { Removal and electrocautery } \\
\text { under LA (headlight) }\end{array}$ & 6 \\
\hline 4. & Female & 57 & 8-Jun & $\begin{array}{l}\text { Nasal mass, intermittent } \\
\text { bleeding, rhinorrhea }\end{array}$ & Left & $\begin{array}{c}\text { Removal and electrocautery } \\
\text { under GA (endoscopic) }\end{array}$ & 6 \\
\hline 5. & Female & 30 & 3 & $\begin{array}{c}\text { Nasal mass, intermittent } \\
\text { bleeding }\end{array}$ & Left & $\begin{array}{l}\text { Removal and electrocautery } \\
\text { under LA (endoscopic) }\end{array}$ & 6 \\
\hline 6. & Female & 24 & $1 \frac{1}{2}$ & $\begin{array}{c}\text { Nasal mass, intermittent } \\
\text { bleeding }\end{array}$ & Right & $\begin{array}{l}\text { Removal and electrocautery } \\
\text { under LA (endoscopic) }\end{array}$ & 6 \\
\hline 7. & Female & 26 & 3 & $\begin{array}{c}\text { Nasal mass, intermittent } \\
\text { bleeding }\end{array}$ & Right & $\begin{array}{l}\text { Removal and electrocautery } \\
\text { under LA (headlight) }\end{array}$ & 6 \\
\hline 8. & Female & 27 & 2 & $\begin{array}{c}\text { Nasal mass, intermittent } \\
\text { bleeding }\end{array}$ & Right & $\begin{array}{l}\text { Removal and electrocautery } \\
\text { under LA (headlight) }\end{array}$ & 6 \\
\hline 9. & Female & 22 & 3 & $\begin{array}{c}\text { Nasal mass, intermittent } \\
\text { bleeding }\end{array}$ & Right & $\begin{array}{l}\text { Removal and electrocautery } \\
\text { under LA (headlight) }\end{array}$ & 6 \\
\hline 10. & female & 25 & 4 & $\begin{array}{c}\text { Nasal mass, intermittent } \\
\text { bleeding }\end{array}$ & Right & $\begin{array}{l}\text { Removal and electrocautery } \\
\text { under LA (headlight) }\end{array}$ & 6 \\
\hline
\end{tabular}

\section{Discussion}

Frank and Blahd M first described LCH as pyogenic granuloma or bleeding polypus in 1940. Again, due to its characteristic microscopic features Mills et al termed pyogenic granuloma as LCH [15]. No malignant transformation has been reported till date in these kinds of benign tumors [7]. As per the literature,
LCH is predominant in females and most commonly occur in the third decade of life [5]. In our series, although two-thirds of the patients were female, supports the idea of higher incidence in the third decade (60\%). The mean age was 30.6 years, ranging from 18 to 57.1 male and 3 females were in the 5 th decade. 2 female patients had a history of oral contraceptives intake. 1 male and 4 
females had history of frequent nose picking habit. In 9 patients, the chief complaints were unilateral rapidly growing nasal mass, intermittent epistaxis and nasal obstruction and rhinorrhea in 1 patient. In 1 male patient (18 years old) the complaint was rapidly growing painless growth in the upper lip. In 1 female patient in the 5the decade the mass was arising from the inferior turbinate (left side) and the rest being from the anterior end of nasal septum (6 on the right side and 2 on the left). The mean duration of symptoms was 2-3 months in the majority however 1 female patient in the 5 th decade was having for 6-8th months and 1 male patient had it since childhood.

Narayanaswamy et al. (2015) study also showed $80 \%(16 / 20)$ of females and $80 \%$ of the study population were in the third decade [7]. 10 had a history of oral contraceptive pills intake. Of the $4 / 20$ male patients, 2 were in the first decade, and 2 in the third decade. Main symptoms were a unilateral nasal obstruction (80\%) and epistaxis $(60 \%)$ which was unprovoked or with trivial trauma. In $14 / 20(70 \%)$ patients the mass was seen arising from the caudal end of the septum, in 4 patients $(20 \%)$ from the anterior end of the middle turbinate and in 2 patients (10\%) from the anterior end of inferior turbinate. Chi et al. (2014) study also showed female predominance $10 / 15$ but no peak incidence was found in the third decade [8].3/15 had diabetes mellitus, hypertension, and rheumatoid arthritis. All patients presented with unilateral nasal complaint with $60.0 \%(9 / 15)$ of the lesions on the left side and $40.0 \%(6 / 15)$ on the right. Main symptoms were epistaxis $(14 / 15$, 93.3\%), followed by nasal obstruction $(12 / 15,80.0 \%)$, rhinorrhea $(8 / 15,53.3 \%)$, protruding tumor $(3 / 15,20.0 \%)$, facial pain $(2 / 15 ; 13.3 \%)$, and headache $(1 / 15 ; 6.7 \%)$. The mean duration of symptoms prior to admission was $3.4 \pm 3.9$ months (ranging from 2 weeks to 12 months). The most common site of the lesion was the anterior nasal septum $(6 / 15,40.0 \%)$, followed by the inferior turbinate $(4 / 15,26.6 \%)$, nasal vestibule $(3 / 15,20.0 \%)$, posterior nasal septum $(1 / 15,6.7 \%)$ (Figure 1$)$, and middle turbinate $(1 / 15$, $6.7 \%$ ). However, Puxeddu et al. study (2006) did not support the idea of female predominance and also the peak incidence being in the fifth decade of life. Predisposing factors such as nasal trauma and pregnancy were identified in $6(15 \%)$ and $2(5 \%)$ patients, respectively. Presenting symptoms were unilateral epistaxis (95\%), nasal obstruction (35\%), rhinorrhea (10\%), facial pain $(7.5 \%)$, headache $(4 \%)$, and hyposmia $(4 \%)$ alone or in different associations and the duration being 1 week to 5 years [9].

In all the study, CECT (contrast enhanced computer tomogram) showed well enhanced soft tissue without bony erosions. The mass was excised via surgical excision and electrocautery either classically with the head light or endoscopically in all the study. Surgical excision is the preferred treatment modality for lobular capillary hemangioma of the nasal cavity. Various surgical treatment modalities include electrocoagulation, cryotherapy, LASER, excisional surgery, and excisional surgery following angiography with embolization (8). In our study, the mass was excised via surgical excision and electrocautery either classically with the head light or endoscopically without preoperative embolization. The recurrence rate ranges from $0 \%$ to $42.0 \%$, depending on the case series and the duration of follow-up [8]. Recurrence was not seen in none of the series. The differential diagnoses of such mass includes nasal polyp, antrochoanal polyp, meningocele, meningoencephalocele, papilloma, wegner's granulomatosis, sarcoidosis, Kaposi sarcoma, hemangiosarcoma, squamous cell carcinoma and mucosal malignant melanoma and in children congenital malformations, dermoid cyst, angiomatous polyp, meningocele, angiofibroma, glioma and schwannoma should be kept in mind. Biopsy of the mass is not recommended by any study due to its vascular origin and high risk of nosebleed.

\section{Conclusion}

LCH is quite a rare benign entity in the nasal cavity region. There is a female predominance with debatable etiology and usually the presenting symptoms are unilateral progressive nasal obstruction and epistaxis of shorter duration. Keeping the differential diagnoses in mind, surgical excision is the definitive treatment modality with less recurrences and minimal morbidity. Awareness of such lesions may help in misdiagnoses of more aggressive entities.

\section{Conflicts of Interest}

The authors declare they have no potential conflicts of interest.

\section{References}

1. Poncet A, Dor L (1897) Botryomycose Humaine. Rev Chir, Paris, France 18: 996.

2. Hartzell MB (1974) Granulation Pyogenicum (Botryomycosis of French Authors). J Cutaneous Dis 22: 520-523.

3. Ramabhadraiah AK, Myle MB, Palegar RV, Mishra U (2014) Pyogenic Granuloma of Nasal Septum: A Case Report and Review of Literature. International Journal of Otolaryngology and Head \& Neck Surgery 3(4): 190-194.

4. Miller FR, DAgostino MA, Schlack K (1999) Lobular capillary hemangioma of the nasal cavity. Otolaryngol Head Neck Surg 120(5): 783-784.

5. Jones JE, Nguyen A, Tabaee A (2000) Pyogenic granuloma (pregnancy tumor) of the nasal cavity: a case report. J Reprod Med 45(9): 749-753.

6. Villarreal IM, Pinilla Urraca M, Garcia Hidalgo, Martin Fragueiro L, Lopez Cortijo C (2014) Nasal lobular capillary hemangioma: Report of 2 cases \& literature review: Journal of Head \& Neck physicians and surgeons 2(2): 92-99.

7. Narayanaswamy GN, Swaroopdev M, Moideen MS, Sherif RM, R Gayathri R (2015) Comprehensive Study on Lobular Capillary Hemangioma of Nose in Tertiary Care Centre: A Retrospective Study. International Journal of Scientific Study 3(5): 126-128.

8. Chi TH, Yuan CH, Chien ST (2014) Lobular Capillary Hemangioma of the Nasal Cavity: Retrospective Study of 15 Cases in Taiwan. Balkan Med J 31(1): 69-71.

9. Puxeddu R, Berlucchi M, Ledda GP (2006) Lobular capillary hemangioma of the nasal cavity: A retrospective study on 40 patients. Am J Rhinol 20(4): 480-484.

10. Winslow DJ (1959) Botryomycosis. The American journal of pathology 35(1): 153-167 
11. Varshney S, Malhotra M, Kaur N, Gairola P (2015) Pediatric Lobular Capillary Hemangioma Nasal Cavity. Clin Rhinol An Int J 8(2): 76-80.

12. Abdelgalil AR (2015) Lobular Capillary Hemangioma of The Lateral Nasal Wall (Case Report). AAMJ 13(4): 75-78.

13. Mills SE, Cooper PH, Fechner RE (1980) Lobular capillary hemangioma: the underlying lesion of pyogenic granuloma. A study of 73 cases from the oral and nasal mucous membranes. The American journal of surgical pathology 4(5): 470-479.
14. Patrice SJ, Wiss K, Mulliken JB (1991) Pyogenic granuloma (lobular capillary hemangioma): a clinicopathologic study of 178 cases. Pediatric dermatology 8(4): 267-276.

15. Mills SE, Cooper PH, Fechner RE (1980) Lobular capillary hemangioma: The underlying lesion of pyogenic granuloma. A study of 73 cases from the oral and nasal mucous membranes. Am J Surg Pathol 4(5): 470-479.

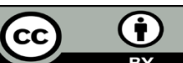

This work is licensed under Creative Commons Attribution 4.0 License

To Submit Your Article Click Here:

Submit Article

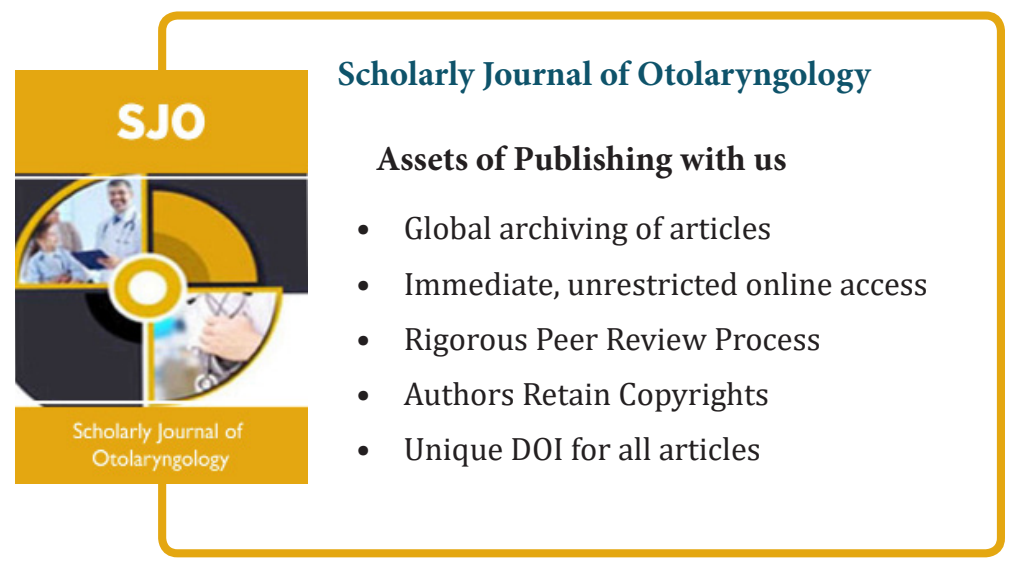

